\title{
A re-evaluation of the breakup of South America and Africa using deformable mesh reconstruction software
}

\author{
Martin Smith \\ Research School of Earth Sciences, The Australian National University, Canberra 0200 Australia \\ Joseph Kurtz \\ Research School of Earth Sciences, The Australian National University, Canberra 0200 Australia \\ Email: joe.kurtz@anu.edu.au \\ Simon Richards \\ Research School of Earth Sciences, The Australian National University, Canberra 0200 Australia

\section{Marnie Forster} \\ Research School of Earth Sciences, The Australian National University, Canberra 0200 Australia

\section{Gordon Lister} \\ Research School of Earth Sciences, The Australian National University, Canberra 0200 Australia
}

Keywords: reconstruction, deformable mesh, Pplates, South America, Africa, breakup 


\begin{abstract}
A software package (Pplates) has been developed which enables tectonic reconstructions to be done with allowances for deformation within and between plates. To do this, the software moves and deforms representations of earth topology by moving and deforming meshes (irregularly tessellated polyhedrons) consisting of planar triangular mesh faces. Each mesh corresponds to a surface represented in three dimensions and placed to conform to the surface of the earth. A general coordinate transformation matrix relating the initial to the final positions of the three vertices of each mesh face is calculated and used analogously to a deformation gradient tensor. When incorporating increasingly detailed intra-plate deformation in a reconstruction, moving objects via a deformable mesh becomes more attractive than creating ever-smaller sub-plates. This paper reviews several tectonic reconstructions of the break up of South America and Africa and demonstrates how they can be enhanced through the use of the reconstruction software.
\end{abstract}




\section{Table of Contents}

Introduction 5

The early fits: Congruent Conjugate Coastlines $\quad$.................................................................

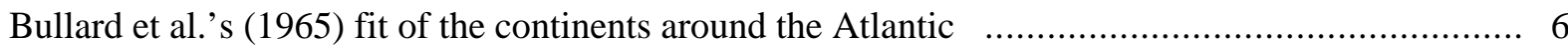

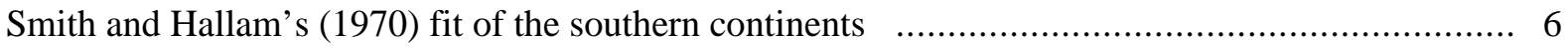

Nürnberg and Müller (1991) utilise improved technology …................................................ 7

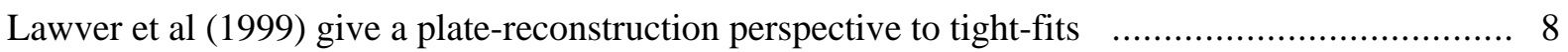

Tectonic reconstructions using deformable mesh software $\quad$................................................... 9

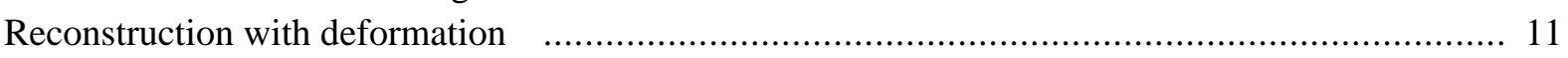

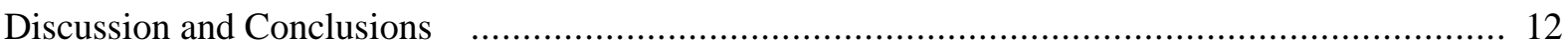

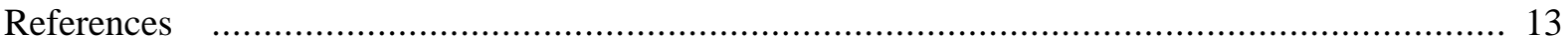




\section{Introduction}

The apparent geometrical fit of South America and Africa provided impetus to the development of plate tectonic theory. The first proposed fits were based on the idea that the two continents behaved as rigid plates (Taylor 1910, originally presented in 1908; Wegener 1912). Taylor and Wegener arrived at their ideas of fit independently, and each argued for past movement of the continents. Both Taylor and Wegener were drawn to suggest past movement of continents based on the fit of the coastlines of South America and Africa. As Wegener notes "continental drift first came to me... under the direct impression produced by the congruence of the coastlines on either side of the Atlantic" (Wegener 1929; pp 1).

Many reconstructions have been developed and published since Taylor and Wegener proposed that the continents have drifted apart. Subsequent reconstructions have attempted to provide an ever-tighter fit between the continents using improved delineation of ocean floor features (marine magnetic anomalies, fracture zones, and the continent-ocean boundary), and this has provided insight into large-scale processes affecting the movement of continents. Still, the remaining misfit was a vexing issue until the proposition of intra-plate deformation along the Benue Trough-Niger Rift in Africa and in the southern parts of South America.

In this paper, the fit of South America and Africa as proposed by Du Toit (1937), Bullard et al. (1965), Smith and Hallam (1970), Nürnberg and Müller (1991) and Lawver et al. (1999) are reviewed. These reconstructions parameterized the continental movements with Euler rotation axes and angles. Though normally derived from relative movement between specific localized areas of each of the continents, the parameters were applied to the entire continents or large areas as though they were rigid throughout history. Intra-continental deformations in reconstructions have usually been accommodated by breaking large rigid plates into smaller rigid plates and applying knowledge of relative movement between areas within a continent, or between two areas of a continent with respect to a third area of another continent. This results in a chain of Euler rotation parameters which mush be linked to each new subplate as deformation is resolved to smaller and smaller scales.

A new software package, Pplates, handles deformations of a continental plate by allowing areas of a continent to move relative to one another while deforming the interstitial areas of the crust accordingly in compression, extension, or shear deformations. In this paper, Pplates is used to present the previous fits using rigid sub-plates and then to include deformations thus introducing a new approach to software-aided tectonic reconstruction.

\section{The early fits: Congruent Conjugate Coastlines}

Like Wegener, Du Toit (1937) also used the apparent congruence of the eastern South American coastline with the western African coastline to derive his fit (Fig. 1), however his argument was not so confined. Du Toit gave a list of several key factors necessary for continental reassembly in conjunction with the similarity of opposed coastlines. These included physiographical, stratigraphical, tectonic, volcanic, palaeoclimatic, palaeontological and geodetic considerations.

\section{Figure 1. Du Toit, 1937.}

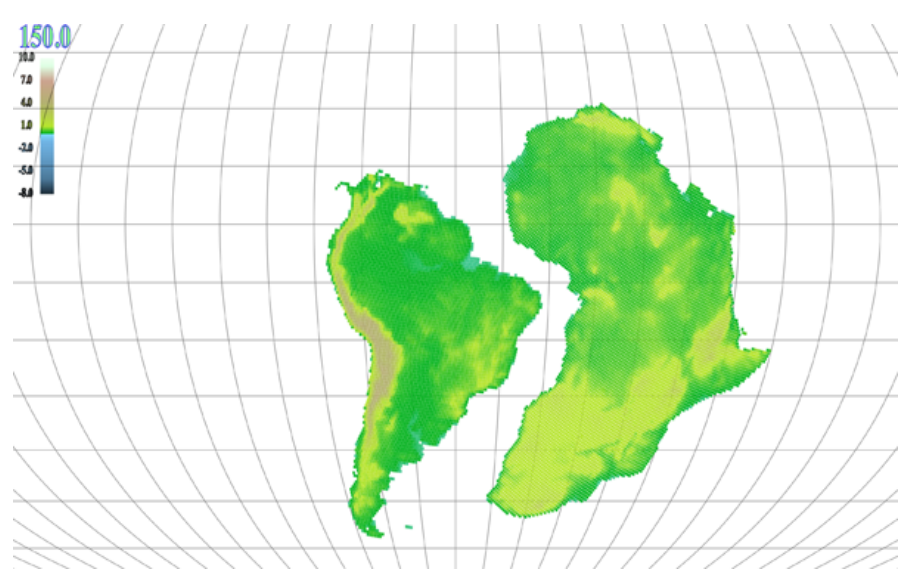

Du Toit's original proposed fit for South America and Africa (Du Toit, 1937) as reproduced by Pplates.

While Du Toit proposed a reconstruction of Gondwana and postulated break-up in the Jurassic with subsequent drift, he did so as evidence for the Continental Drift hypothesis. Du Toit's best fit estimate for Africa and South America suggested a 250 - to $350-\mathrm{km}$ separation of the coastlines. He recognised that subsequent tectonic and erosional processes have influenced the fragments, and thus modified their outlines. He stated that the mismatch arrived at using the current coastlines of South America and Africa can be explained by land "lost after fracture and during drift by erosion and/or submergence, much of it perhaps going to form the continental shelves". Du Toit argued that the 
use of the continental shelf as the edge of the continent is no better than the use of the coastline.

\section{Bullard et al.'s (1965) fit of the continents around the Atlantic}

Bullard et al.'s (1965) fit (Fig. 2) was arrived at using "modern" numerical methods. The data came from the contours on maps of the world provided by the U.S. Hydrographic service (1961). The maps provided 100 , 500and 1000 fathom contours. Thus, the fits were tested using these as the depths of continental shelf. The numerical method was based on the application of Euler's Theorem to the movement of points on a line across a sphere. In this case, Bullard et al. utilised this method to define the displacement of a contour line (or continent) as a rigid rotation. The best fit was arrived at by choosing a point, Pn, on the contour of the western continent, and finding a corresponding point, $\mathrm{P}$ 'n, on the eastern continent at the same distance from the centre of rotation. After a rotation, the misfit was described by the square of the difference in longitude between such points, summed over all points on the eastern contour. The best fit rotation minimised this sum (i.e. a "least squares method").

Figure 2. Bullard, et al., 1965.

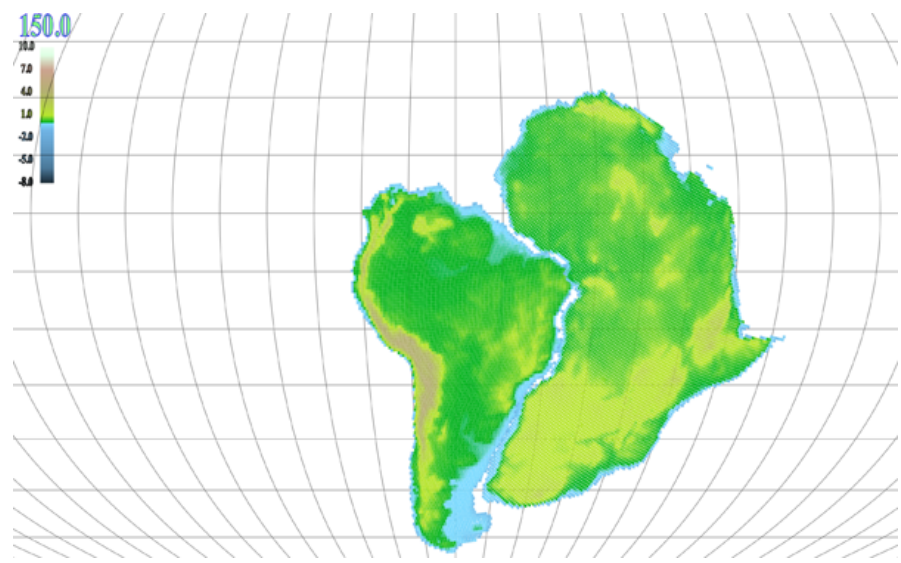

Pplates reconstruction using the Bullard et al. (1965) rotation parameters for South America relative to Africa. Africa has been rotated according to the Global Isochron Chart (Royer et al. 1992)

The best fit was found to occur when the 500-fathom (914.4 m) contour was used as the continental boundaries with the rotation listed in Table 1 . This process resulted in a root-mean-square misfit of about $130 \mathrm{~km}$ for South America to Africa. The reconstruction technique was seen as providing a first-step approach for which correlation of various geological features across the region was still required. The two areas of greatest misfit, the Niger delta and the Walvis Ridge, were taken to correspond to areas of post break-up features: The Niger delta was taken to be a Tertiary feature, and the Walvis Ridge as being related to the Tertiary Mid-Atlantic Ridge.

Table 1. Euler rotations for continental South America relative to Africa from early proposed fits.

\begin{tabular}{|c|c|c|c|c|c|}
\hline $\begin{array}{c}\text { Mobile } \\
\text { plate: S. } \\
\text { Ameri- } \\
\text { ca }\end{array}$ & $\begin{array}{c}\text { Age } \\
\text { (Ma) }\end{array}$ & Lat & Lon & Angle & $\begin{array}{c}\text { Rela- } \\
\text { tive to }\end{array}$ \\
\hline $\begin{array}{c}\text { Du Toit } \\
(1937) \\
\text { (est'd.) }\end{array}$ & Jurassic & 49 & -28 & 46 & Africa \\
\hline $\begin{array}{c}\text { Bullard } \\
\text { et al. } \\
(1965)\end{array}$ & $\begin{array}{c}\text { U. Ju- } \\
\text { rrasic }\end{array}$ & 42.9 & -30.1 & 57.1 & Africa \\
\hline $\begin{array}{c}\text { Smith } \\
\text { and Hal- } \\
\text { lam } \\
(1970)\end{array}$ & $\begin{array}{c}\text { U. Ju- } \\
\text { rrasic- } \\
\text { L. Cre- } \\
\text { taceous }\end{array}$ & 44 & -30.6 & 57 & Africa \\
\hline
\end{tabular}

\section{Smith and Hallam's (1970) fit of the southern continents}

Smith and Hallam (1970) proposed a fit of South America and Africa (Fig. 3) as part of a reconstruction of "Gondwana". They based their reconstruction on similar methods to Bullard et al. (1965), using the 914-m contour as the edge of the continent, and rotation data for their best fit is shown in Table 1. The most important feature of the Smith and Hallam reconstruction is in the utilisation of geological and geophysical evidence to support their reconstruction. Geological evidence cited includes the continuation of the West African shield into the Sao Luis of northern Brazil based on age determinations, the extension of a Pre-Cambrian sequence from the Bahia of Brazil into Gabon, the close match of structures and sedimentary sequences between Argentina and South Africa, and the cross-cutting relationship of the Palaeozoic "Brazilides" fold belt and the Palaeo - Mesozoic "Gondwanide" fold belt. 
Figure 3. Smith and Hallam, 1973.

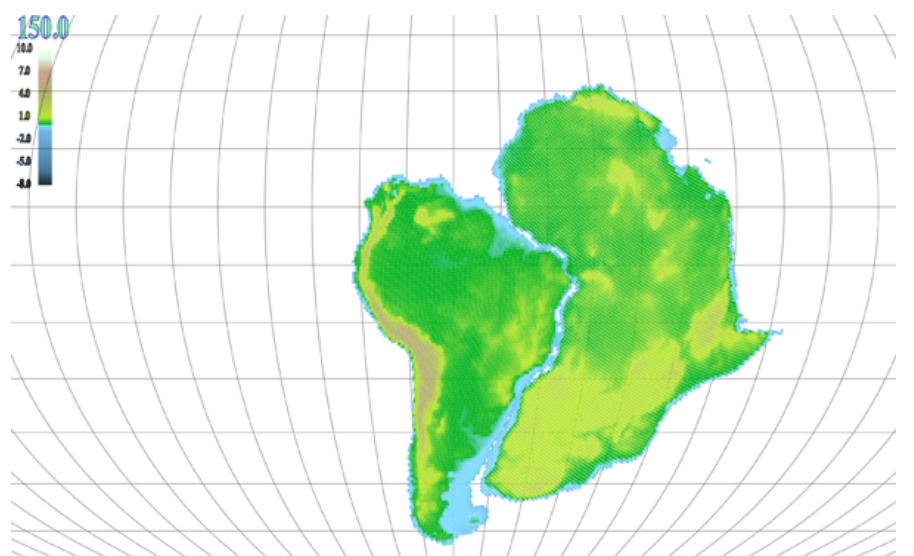

Pplates reconstruction using the Smith and Hallam (1970) rotation parameters for South America relative to Africa. Africa rotated according to the Global Isochron Chart (Royer et al. 1992)

Smith and Hallam also utilised palaeontological, sedimentary, and igneous evidence to postulate when the break-up of Gondwana could have initiated. Based primarily on evidence of the Serra Geral volcanism in the Parana Basin, thought to be related to break-up because it occurs primarily along the continental margin, they concluded break-up began between the Upper Jurassic and Lower Cretaceous. Neritic sediments along the African and South American margins suggested a slightly later, Middle Cretaceous time for break-up. Palaeomagnetic evidence based on differences in apparent polar wander paths suggested dispersal occurred at $100 \mathrm{Ma}$, but this was not conclusive in the case of Africa and South America as sea-floor spreading rates increased in the South Atlantic at about 120 Ma, subsequent to initial Jurassic rifting.

This reconstruction gathered evidence from multiple sources, and incorporated it into a complex model for the timing of break-up. The advent of large geological datasets and improved computing facilities has subsequently enabled better-constrained, more complex reconstructions.

\section{Nürnberg and Müller (1991) utilise improved technology}

In their reconstruction of the tectonic history of the South Atlantic since the Jurassic, Nürnberg and Müller (1991) aimed to provide a complete history of the separation of Africa from America from a fit position to the present day.
Nürnberg and Müller utilised a recent marine magnetic anomaly compilation and the vertical deflection data obtained from the GeoSat database to substantiate the previously existing marine magnetic anomaly database with the tectonic flow directions and lineations. From this compilation, they established that the first ocean crust formed during with marine anomaly M4 (126.5 Ma) and abuts the continent-ocean boundary. Consequently, the authors defined their continental plate boundaries as the continentocean boundaries modified from that of Emery and Uchupi (1984) by Gahagan et al. (1988) using GeoSat data.

As well as an improved marine data, Nürnberg and Müller incorporated intra-continental extension and strikeslip movement. In South America, they focussed on the Parana-Chacos, Colorado, and Salado basins, and proposed addition crustal extension in NE Brazil. In Africa, they invoked movement along the Benue Trough/Niger Rift system. Movement in these systems was assumed to have been prior to or during break-up.

Figure 4. Nurnberg and Muller, 1991.

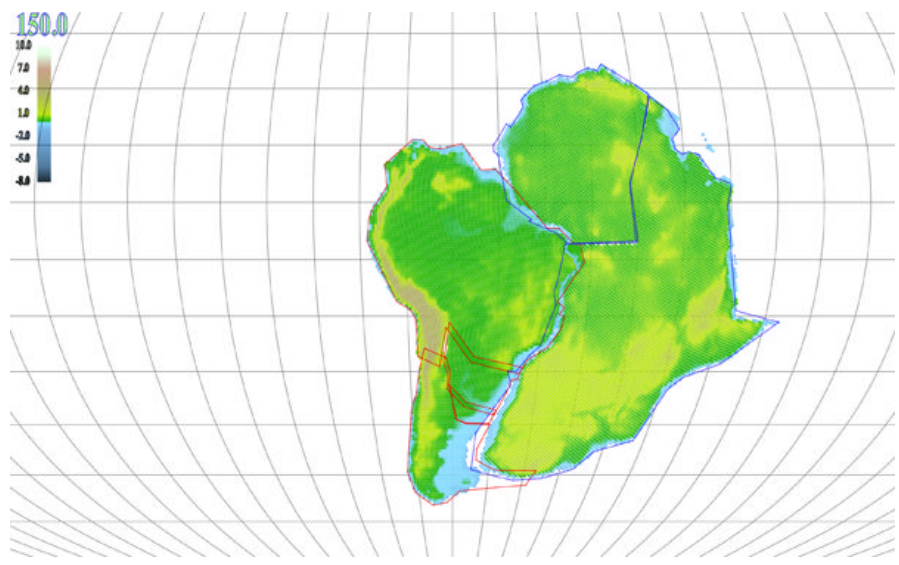

The rigid-plate reconstruction of Nürnberg and Müller (1991) as presented by Pplates. Africa has been rotated according to the Global Isochron Chart (Royer et al. 1992)

Their model supposes that the initial rifting in the southern Atlantic region at $150 \mathrm{Ma}$ progressed northward to $\sim 380$ S when rifting in the Colorado basin began. Subsequent northward propagation of the rift caused deformation in the Salado basin and in the Parana-Chacos basin from 130 to $126.5 \mathrm{Ma}$. The rift continued northward into the $\mathrm{Ni}$ ger Rift area, inducing rifting and strike-slip motion between 126.5 and $118.7 \mathrm{Ma}$. The Niger Rift failed by $84 \mathrm{Ma}$, following which the Atlantic opened by divergence between the Guinea and Demarara Plateaus (with additional 
crustal extension in NE Brazil) thus separating the South American and African plates.

This model was accommodated by breaking southern South America into three sub-plates (the Colorado, Salado, and Parana) and breaking NW Africa from Africa along the Benue Trough/Niger Rift system. Their initial fit at $150 \mathrm{Ma}$ was based on a reconstruction of the equatorial Atlantic, matching the Guinea and Demarara Plateaus and fracture zones from GeoSat data. They then applied a rotation of (southern) Africa relative to NW Africa to close the Benue Trough and Niger Rift, thus assuming the Trough to represent around $50 \mathrm{~km}$ of rifting with some strike-slip movement as it opened. The overlaps in the continental-ocean boundaries of Africa and South America were then explained by invoking subsequent extension and shear in South America. Overlap of NE Brazil, they hypothesized, could be compensated for by invoking extensions in the Reconcavo and Tucano basins during the earliest phase of rifting there. Overlaps of continent-ocean boundaries further south were countered by reversing $\sim 65 \mathrm{~km}$ of rifting and $20 \mathrm{~km}$ of strike-slip motion in the region of the ParanaChacos Basin. The southernmost overlap is reversed by the extensions of the Salado and Colorado basins, representing $\sim 20 \mathrm{~km}$ of rifting and $\sim 40 \mathrm{~km}$ of strike-slip motion, and $\sim 40 \mathrm{~km}$ rifting and $20 \mathrm{~km}$ of slip, respectively, since the middle Jurassic.

Nürnberg and Müller (1991) provided a comprehensive rotation history resulting in a tight fit of Africa and South America. Each sub-plate to be moved rigidly was assigned the Euler poles shown in Table 2. Figure 4 shows their rigid reconstruction as rendered by Pplates. The boundaries depicted in the figure were drawn to emulate the overlap given by the authors original paper, but they were also extended in order to close those boundaries around the rigid regions. Pplates applied the rotation data to the enclosed regions and the resulting overlap (and some separation in NW Africa) of the boundaries can be seen in the figure.

Even though tectonic reconstructions have become more complex as larger, more varied datasets were incorporated, the use of rigid sub-plates does not accurately model crustal deformation.
Table 2. Euler rotations for final fit of South America and Africa (including intra-plate motions) from Nürnberg and Müller (1991)

\begin{tabular}{|c|c|c|c|cl|}
\hline $\begin{array}{c}\text { Mobile } \\
\text { plate }\end{array}$ & $\begin{array}{c}\text { Age } \\
\text { (Ma) }\end{array}$ & Lat & Long & Angle & $\begin{array}{l}\text { Rela- } \\
\text { tive to }\end{array}$ \\
\hline $\begin{array}{c}\text { S. } \\
\text { America }\end{array}$ & 131.5 & 50 & -32.5 & 55.08 & Africa \\
\hline Parana & 131.5 & -15.2 & -73.2 & 1.48 & $\begin{array}{l}\text { S. } \\
\text { America }\end{array}$ \\
\hline Salado & 150 & -32.2 & -64.5 & 1.18 & Parana \\
\hline $\begin{array}{c}\text { Colora- } \\
\text { do }\end{array}$ & 150 & -18 & -73.2 & 1.05 & Parana \\
\hline $\begin{array}{c}\text { NW Af- } \\
\text { rica }\end{array}$ & 118.7 & 16.5 & 6.7 & -1.15 & Africa \\
\hline
\end{tabular}

\section{Lawver et al (1999) give a plate- reconstruction perspective to tight-fits}

The innovative approach used by Lawver et al in constraining the fit of the southern continents was their use of gravity data to constrain the continent-ocean boundary. The reconstruction (Figure 5) is based on marine magnetic anomalies, other seafloor age data, seafloor bathymetric features and tectonic fabrics indicating past motion directions determined from satellite altimetry. The authors utilised an absolute palaeomagnetic reference frame to derive motions back to $130 \mathrm{Ma}$, and a combined hotspot (Coffin and Eldholm, 1994) and palaeomagnetic reference frame (Van der Voo, 1993) to calculate a new framework back to $200 \mathrm{Ma}$. This study also utilised a purpose-built software package, Plates, to visualise the fit and subsequent rotation history of Gondwana. The authors proposed mantle plumes as a trigger for the break-up of Gondwana and, more specifically, the Parana - Etendeka plume for triggering the initial split of South America from Africa at $132 \mathrm{Ma}$. 
Figure 5. Lawver, et al., 1999.

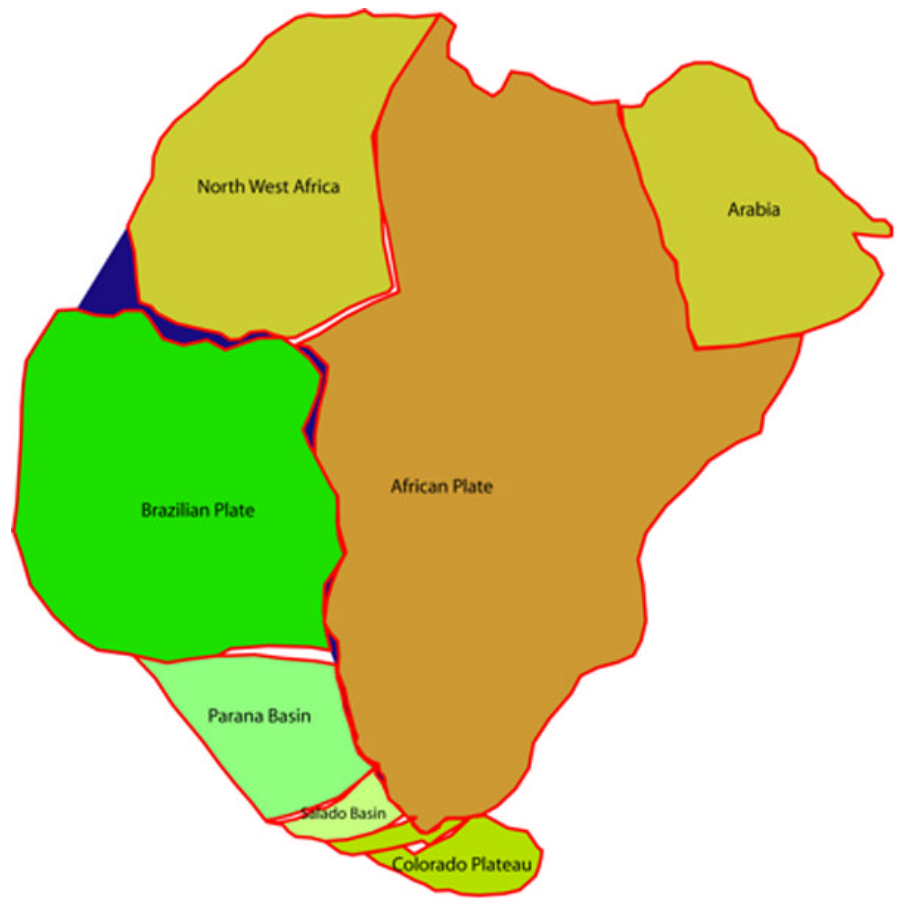

Detailed image of the Lawver et al. (1999) tight fit for South America and Africa.

The South America - Africa fit proposed by Lawver, et al, is illustrated in Figure 5. As with the fit of N\&M described previously, Lawver, et al, utilised movement/rifting to account for some of the misfit: in the Parana Basin, within the Colorado Basin, around the Falkland Islands microplate, and in the West African Rift. Lawver, et al., mentioned three overlaps: two deltaic (the Niger and Amazon Deltas) deposits are accounted for as they are postbreak-up features. The third overlap is in the region of the Abrolhos and Royal Charlotte Banks, which are a result of magmatic activity post-dating break-up by $80-100$ million years. These overlaps appear only to be of the shallower regions of the continental margins (green outlines in Figure 9). Some apparent overlap of the deeper margin areas around the Colorado Basin/southern Africa region and the Falkland Islands/southern Africa region is not addressed by the authors and may be a result of discrepancies between the gravity data and the present continental boundary. Lawver et al. did not publish their Euler rotation data.

\section{Tectonic reconstructions using deformable mesh software}

Plate tectonic theory has evolved largely using the notion of rigid plates. Accordingly, the movement of plates (on the sphere) can be exactly described using rotations, typically specified by the Euler pole (axis) and rotation angle. However, the continental masses do not behave rigidly, and therefore this has been a mismatch in terms of geodynamic theory. It has been possible approximate the continuous deformation of orogenic belts by using rigid subplates, but such applications eventually require many different hierarchical movements. To allow plate tectonic theory to be extended to take account of the deformation of continents, and marginal orogens, a new generation of reconstruction software is necessary.

Pplates (http://access.edu.au/) allows movement and deformability via the use of meshes (irregularly tessellated polyhedrons) consisting of points (mesh nodes) connected to one another by straight lines forming planar triangular mesh faces (Figure 6). Each mesh corresponds to a surface internally represented in three dimensions with nodes initially connected using a Delauney algorithm and placed to conform to the surface of the earth. The earth topology is then adopted ("classified" as crust) in the meshed areas and moved with the mesh. 


\section{Figure 6. A Pplates Mesh.}

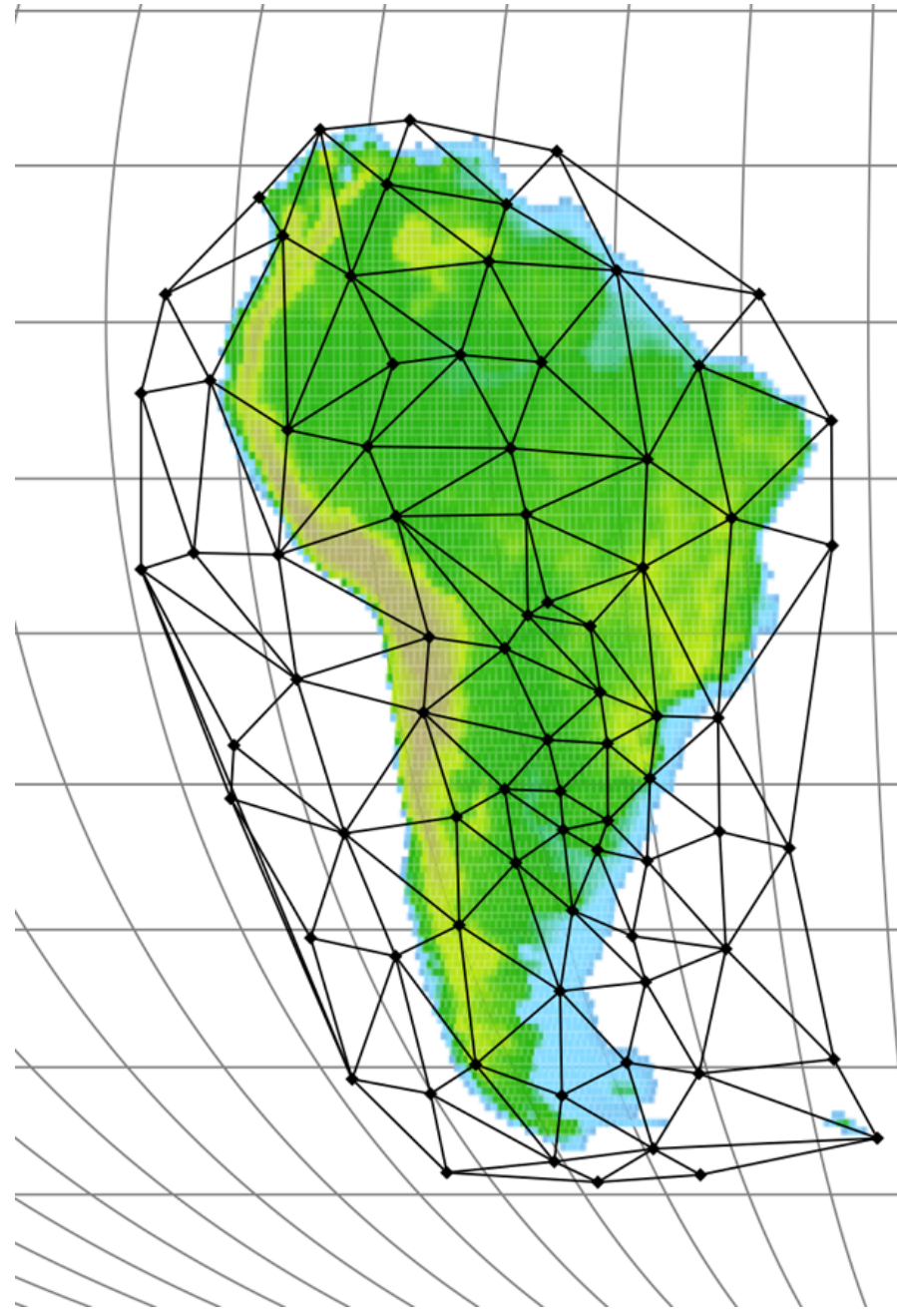

A mesh as shown by Pplates which is placed over South America for moving and deforming the continent.

samesh.png (440 kb, 19/10/06)

A movement of a mesh face without deformation (rigidly) to anywhere on the earth's surface corresponds to an Euler rotation. This rotation can be expressed as a 3-by-3 matrix, $\mathrm{R}$, in Cartesian coordinates which can be used to transform the Cartesian coordinates of any point associated to the mesh face (i.e. the nodes or the interior points). When moving a point of latitude and longitude in the interior of a mesh face, the equivalent Cartesian coordinates are calculated and expressed as a vector, $\mathrm{X}$, then the product of the rotation matrix and the vector produces a new vector of Cartesian coordinates, $\mathrm{X}$ :
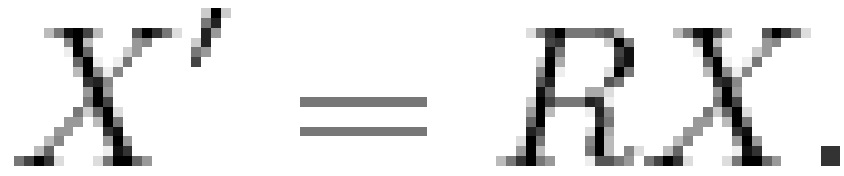

The new vector is used to calculate the new latitude and longitude of the point after rotation, but the new altitude is assigned, either being left unchanged or modified depending on the user's choice of options (e.g. application of crust conservation and isostasy).

To include both the movement and deformation of a mesh face, Pplates uses a more general formulation of the rotation matrix. Given the three initial and final Cartesian vectors of the three nodes of a mesh face, the transformation matrix F can be calculated directly as follows: Let the matrix $\mathrm{N}$ be constructed as columns of the initial Cartesian vectors and $\mathrm{M}$ be the matrix similarly constructed from final vectors. The matrix equation $\mathrm{M}=\mathrm{F} \mathrm{N}$ then holds, whence

$$
\bar{F}=\left(M N^{T}\right)\left(N N^{T}\right)^{-1}
$$

$\mathrm{F}$ is a general coordinate transformation relating the initial three vector axes to the final three axes of different orientation and lengths. As such, it is completely analogous to a deformation gradient tensor. F can be decomposed into a rigid rotation matrix $\mathrm{R}$ and either of the two stretch matrices V or U (i.e. polar decomposition)(Malvern 1969):

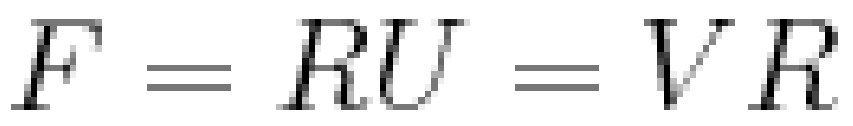

where

$$
U^{2}=\left(F^{T} F\right) ; V^{2}=\left(F F^{T}\right)
$$

Both $\mathrm{U}$ and $\mathrm{V}$ are symmetric, positive-definite matrices. This decomposition exists and is unique as long as $\mathrm{F}$ is invertible. The rotation matrix can then be calculated as<smiles></smiles>

For a movement over the surface of a sphere, R corresponds to an Euler rotation, and V or U perform stretches 
of the original configuration. In practice, however, the matrix $\mathrm{F}$ is used in whole in place of the Euler rotation matrix whenever points associated to a (deforming) mesh face are to be moved (altitude being handled as described above).

As a particularly convenient feature, Pplates allows a mesh to be subdivided. This involves designating a subset of nodes of an existing mesh to also be nodes of a smaller, coexisting mesh - a "submesh" - thus giving them "dualcitizenship". In the simplest use case, plate-deforming movements can be described by the relative rotation of submeshes within the larger mesh with the resulting deformation confined to the intervening regions. A submesh enables movement emulating the sub-plates commonly used in reconstructions. The notable difference is that moving a submesh does not disconnect it from its parent mesh and no overlaps or gaps are created, but rather the interconnecting faces are deformed.

\section{Reconstruction with deformation}

To demonstrate the simplest enhancement using deformability, we have re-created the reconstruction of Nürnberg and Müller (1991) with Pplates using deformable meshes. Africa was assigned a motion history for the last $160 \mathrm{Ma}$ from the Global Isochron Charts of Royer et al. (1992) while a submeshes were created within the Northwest Africa, the Parana, the Colorado, and the Salado subplates, each assigned to their rotation history from Table 2 . As each submesh moved, any consequent intra-plate deformation occurred between them. The final resulting fit at $150 \mathrm{Ma}$ is compared in Figure 7 with the rigid-plate reconstruction of Figure 4.

\section{Figure 7. Deformable Fit Comparison.}

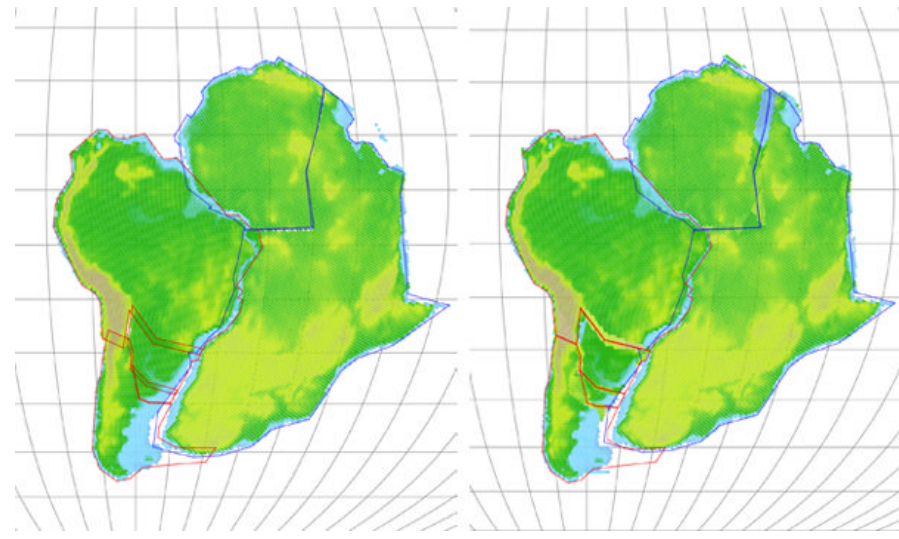

The final fit of Nurnberg and Muller (1991) using deformable continents (right) compared with that of Figure 4 (left) at $150 \mathrm{Ma}$.
The deformations shown in this reconstruction (Figure 7) were confined to the small areas along the boundaries between the sub-plates. Pplates has represented these extensional regions as compressed relative to modern day. By starting with modern-day topology, assumed isostasy, and crustal volume conserved, Pplates thus calculated an increase in altitude for these regions. Though the detailed distribution of this altitude change depends on the details of the mesh construction and the calibration of the isostatic calculation, when the deformations are spread realistically over the basin regions, we could expect the elevation change to correspond to the depth to the basement of the sediment in the modern-day basins. Pplates has the ability calculate this information given sufficient geological information and precisely located meshes of sufficient granularity for the areas of interest. In contrast, the rigid plate reconstruction shows the overlap areas and gaps of the rigid sub-plates but can not indicate the extent of deformations or its implications for changes in topography.

A tight-fit similar to that presented by Lawver et al. (1999) was arrived at using the motion histories for South America and Africa as taken from the Global Isochron Chart of Royer, et al., (1992) and performing intra-plate deformation using submeshes for the Parana, Salado basins and NW Africa. The timings of the deformations were drawn from Müller et al. (1993) and Unternehr, et al., (1988) as described below. An animation of the reconstruction from present day to $160 \mathrm{Ma}$ (Figure 8) was done using Pplates.

Figure 8. Animated Reconstruction with Deformation.

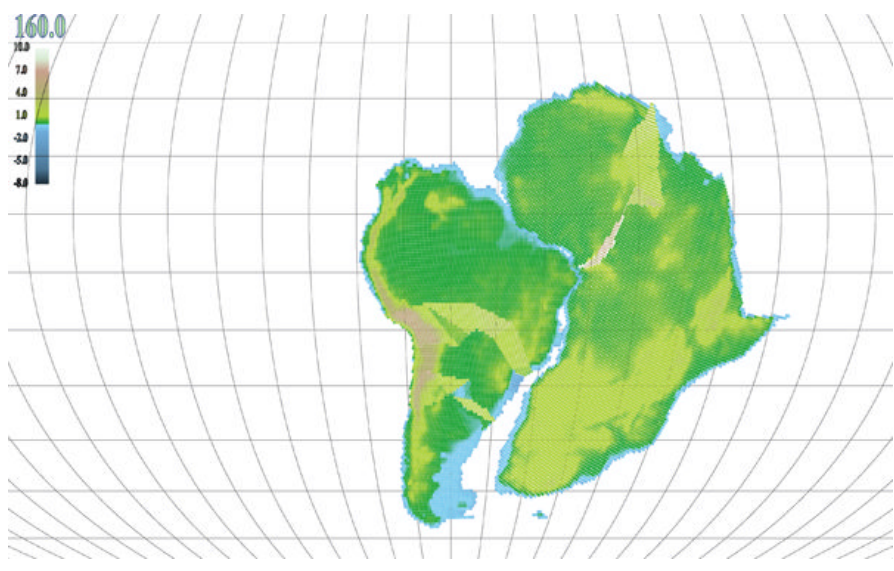

An animation of the reconstruction from present day to 160 Ma done using Pplates with deformable continents on the basis of the Global Isochron Chart (Royer et al. 1992) with timings established as described in the text. 
In the case of Africa, Müller et al. (1993) suggested onset of rifting in the Benue trough region to be at or before 130.7 Ma and to be complete between 100 and $90 \mathrm{Ma}$. Interpolated motions from an earlier Pplates reconstruction using separate rigid plates and Euler histories for Africa and NW Africa based on this model showed the two regions to stop spreading between 98 and $95 \mathrm{Ma}$. A submesh in NW Africa was then used for closure of the Benue Trough/ Niger Rift region starting around 95 Ma. Working backward in time, the submesh was moved in such a way as to preserve the geometry of NW Africa while the Benue trough region was compressed. (It is important to remember that reversing the temporal references also reverses the sense of deformation, 'extension' vs. 'compression', when doing a Pplates reconstruction.) Deformation of the mesh was completed by $130.7 \mathrm{Ma}$, the beginning of extension according to Müller et al. (1993). The degree of deformation was derived from the relative motion of NW Africa to Africa (Royer, et al., 1992) as Africa itself was rotated relative to the palaeomagnetic reference frame (Royer, et al., 1992).

For South America, the two regions that were deformed equate to the Salado and Parana Basins as described by Unternehr, et al., (1988) and subsequent workers. Using Euler histories for South America (Royer et al. 1992) and the same procedure as for Africa, deformation within the Salado Basin was initiated at between 130 and $150 \mathrm{Ma}$ and ceased between 118 and $120 \mathrm{Ma}$; in the Parana Basin, extension was already underway at $150 \mathrm{Ma}$ and approaching its terminal stages around $130 \mathrm{Ma}$.

\section{Discussion and Conclusions}

The reconstructions reviewed here are a representative sample of the historical literature on the development of the fit of South America and Africa. The ideas of Wegener and Du Toit have evolved beyond simple "coastline matching," and today the best model is provided by using gravity data to locate the continent-ocean boundary, marine magnetic anomalies and transforms as constraints on ages and magnitudes of rotation, and incorporating intra-plate deformation and rifting. Royer et al. (1992) provided the most detailed model.

Previous rigid-plate reconstructions were presented and compared with deformable-mesh reconstructions using Pplates. The areas of deformation were tightly restricted to a few areas of known extensional zones, though the user per his knowledge or hypotheses can change this. Applying crustal volume conservation and isostasy result in elevation changes in the deformed zones. Although the information displayed is generally qualitative, we could expect an elevation increase to correspond to the depth to the basement of the sediment in the modern-day extensional basins when realistic deformation regions are defined.

A special note must be taken with deformable plates: representing the movement of an entire plate with a single Euler rotation is inadequate. To continue to use Euler rotations, it is necessary to specify the two regions of the earth linked by the measurement of the rotation. These regions should be as small as possibly allowed by the geology and geophysics of the measurement itself. For example, if we wished to use an Euler rotation to represent, say, the movement of a craton in southern South America relative to a craton in NW Africa, we would not pressume that it represents the movement of regions larger than the cratons involved without further evidence. As more movement data accumulates for different areas of each continent/plate (relative to one another or to a common reference frame), then deforming the continent as done by Pplates becomes more attractive than creating ever-smaller sub-plates. There is an added advantage in that the deformed regions depicted by Pplates can be made to conform to regions of known geological deformation, if desired, thus creating more geologically-constrained reconstruction scenarios.

Further development of Pplates will refine and extend the use of meshes as a device for simulating the three-dimensional movements of both surface and subducted lithosphere in tectonic reconstructions. With the formalism discussed in this paper, Pplates is able to calculate the crustal/lithospheric strain induced by the deformations. Also presently being incorporated into this software is a model of mesh faces that includes stress (forces) between mesh nodes. The model incorporates elasticity (Hooke's Law) and can also include viscosity. Thus it is possible to introduce stresses in the mesh via deformations (strain) and distribute stress and strain throughout the mesh over time.

Since this pseudo rheology is only the first instance of a more general introduction of constraints, Pplates will increasingly become a simulator rather than a kinematic visual reconstruction aid. Simulation will include constraining movements using both geological data and the adaptation of rules based on the geophysics of lithospheric deformation and tectonic processes on a global scale. The latter will be drawn both from observations and the insight gained from forward modelling using high-performance 
computer (HPC) codes. Observations now include meshes built from seismic tomography images of subducted slabs which, when included in reconstructions with appropriate pseudo rheology, will constrain hypothetical reversals of subduction zone processes. Further to this, we plan to use Pplates as an interface to such HPC forward-modelling capability that can model the subduction in the time-forward direction and provide plausibility to a hypothetical reconstruction of an initial subduction zone of the ancient earth.
By developing and applying such technology, we hope to provide valuable contributions to the modelling and reconstruction of Gondwana, in particular, and especially the Arica Bend of South America including the development of sub-Andean basins and the evolution of the East African Rift system. This will give a more comprehensive reconstruction of the break up of Gondwana. 


\section{References}

Bullard, E., Everett, J. E. and Smith, A. G. (1965). "The Fit of the Continents around the Atlantic." Philosophical Transactions for the Royal Society of London. Series A, Mathematical and Physical Sciences 258(1088, A Symposium on Continental Drift): 41-51.

Du Toit, A. L. (1937). Our Wandering Continents. Edinburgh, Oliver and Boyd.

Emery, K. O. and Uchupi, E. (1984). The geology of the Atlantic Ocean. New York, Springer.

Jokat, W., Boebel, T., Konig, M. and Meyer, U. (2003). "Timing and geometry of early Gondwana breakup." Journal of Geophysical Research 108(B9): 2428-2443.

Lawver, L. A., Gahagan, L. M. and Dalziel, I. W. D. (1999). A tightfit Early Mesozoic Gondwana: A plate reconstruction perspective. International Symposium "Origin and Evolution of the Continents". Memoirs of the National Institute of Polar Research, Special Issue. Motoyoshi, Y. and Shiraishi, K. Tokyo, National Institute of Polar Research 53: 214-229.

Nurnberg, D. and Muller, R. D. (1991). "The tectonic evolution of the South Atlantic from Late Jurassic to present."

Tectonophysics 191(1-2): 27.

Royer, J.-Y., Müller, R. D., Gahagan, L. M., Lawver, L. A., Mayes, C. L., Nurnberg, D. and Sclater, J. G. (1992). A global isochron chart. University of Texas Institute for Geophysics Technical Report: 38.
Schettino, A. (1998). "Computer-aided paleogeographic reconstructions." Computers \& Geosciences 24(3): 259.

Schettino, A. and Scotese, C. R. (2005). "Apparent polar wander paths for the major continents (200 Ma to the present day): a palaeomagnetic reference frame for global plate tectonic reconstructions." Geophysical Journal International 163(2): 727-759.

Smith, A. G. and Hallam, A. (1970). "The Fit of the Southern Continents." Nature 225(5228): 139.

Taylor, F. B. (1910). "Bearing of the Teritiary mountain belt on the origin of the Earth's plan." Bulletin of the Geological Society of America 21: 179-226.

Unternehr, P., Curie, D., Olivet, J. L., Goslin, J. and Beuzart, P. (1988). "South Atlantic fits and intraplate boundaries in Africa and South America." Tectonophysics 155(1-4): 169.

Wegener, A. (1912). "Die Entstehung der Kontinente." International Journal of Earth Sciences 3(4): 276.

Wegener, A. (1929). The Origin of Continents and Oceans. London, Methuen. 